Article

\title{
The Energy Audit Activity Focused on the Lighting Systems in Historical Buildings
}

\author{
Giacomo Salvadori, Fabio Fantozzi, Michele Rocca and Francesco Leccese * \\ Lighting and Acoustic Laboratory (LIA), Department of Energy, Systems, Territory and Constructions \\ Engineering, University of Pisa, Largo Lucio Lazzarino, Pisa 56122, Italy; giacomo.salvadori@unipi.it (G.S.); \\ f.fantozzi@ing.unipi.it (F.F.); michele.rocca.au@gmail.com (M.R.) \\ * Correspondence: f.leccese@ing.unipi.it; Tel.: +39-050-221-7136
}

Academic Editor: Rodolfo Araneo

Received: 28 September 2016; Accepted: 21 November 2016; Published: 27 November 2016

\begin{abstract}
The energy audit for a building is a procedure designed mainly to obtain adequate knowledge of the energy consumption profile, identify, and quantify opportunities for energy savings by a cost-benefit analysis and report, clearly and comprehensively, about the obtained results. If the audit is referred to a building with a significant historical and artistic value, a compatibility evaluation of the energy saving interventions with the architectural features should also be developed. In this paper, analysing the case study of a historical building used as public offices in Pisa (Italy), the authors describe how it is possible to conduct an energy audit activity (especially dedicated to the lighting system) and they show how, for this type of buildings, it is possible to obtain significant energy savings with a refurbishment of the lighting system. A total number of seven interventions on indoor and outdoor lighting sub-systems were analysed in the paper. They are characterised by absolute compatibility with the historical and artistic value of the building and they show short payback times, variable between 4 and 34 months, allowing a reduction of the electrical energy consumption for the artificial indoor and outdoor lighting variable from 1.1 MWh/year to 39.0 MWh/year. The followed methodology and the evaluation results described in the paper, although based on a case study, can be extended to numerous historical buildings used as public offices, a recurring situation in the centres of Italian historical cities.
\end{abstract}

Keywords: energy saving; energy audit; historical buildings; lighting systems; lamps replacement

\section{Introduction}

The energy audit for an existing building is a procedure designed mainly to obtain an adequate knowledge of the energy consumption profile, identify and quantify the opportunities for energy savings by a cost-benefit analysis, and report, clearly and comprehensively, about the obtained results [1]. Therefore, for energy audit should be considered a systematic procedure which begins with survey operations and with the acquisition of the historical consumption data of the building, proceeds through the use of appropriate simulation models for the energy performance of the building, and finishes with the identification and analysis of energy-saving opportunities based on cost-effectiveness evaluations. If the audit refers to an existing building with a significant historical and artistic value a compatibility evaluation of the energy saving interventions with the architectural features should be also added to the above indicated stages, which requires a multidisciplinary and well-structured analysis [2-5].

The relevance of Italian cultural heritage is universally recognized, considering that it is rated as first for the number of sites registered as "heritage of humanity" in the UNESCO World Heritage List [6]. The historical city centres contain most of the cultural heritage; in fact, in the entire stock of Italian residential buildings, almost two out of ten buildings are built before 1900. In absolute terms, 
nowadays in Italy there are over two million historic buildings used. The buildings with significant historical and artistic value are frequently assigned to public functions, and they are used as offices or similar activities and are generally characterized by poor energy performance. With particular reference to the buildings used as public offices, for which the energy consumption is mainly due to winter heating, summer cooling, and artificial lighting, a national average value of the annual energy consumption of about $500 \mathrm{kWh} / \mathrm{m}^{2}$ year is estimated [7], far away from the performance of the energy efficient buildings and from the requirements fixed by the municipal building regulations for energy saving [8-11]. In the historical buildings, this situation is further exacerbated because the envelope structures have not been designed in accordance with the optimization of energy performance criteria and the volumes are usually of considerable size [12,13]. However, the interventions that allow a significant improvement of the building envelope performance, in terms of thermal insulation and humidity behaviour, are usually invasive. They are made predominantly in the opaque portion of the building envelope (the main portion, especially for historical buildings) and they generally provide for the laying of a thermal insulating layer on the outer side (external insulating coating) or on the inner side (counter-wall or false ceiling with insulation material) of the existing building structures. The possibility to carry out such interventions, regardless of the economic benefits, should be assessed case by case in order to ensure the preservation of the historical and architectural value of the building.

The energy saving interventions that involve the refurbishment of the lighting systems are, on the contrary, generally minimally invasive (especially in the case of re-lamping or the installation of automatic systems for control and management of the lighting) and they can be leave unchanged the architectural value of the buildings. In addition, for office buildings (a frequent function attributed to the Italian historical buildings) the energy consumption due to artificial lighting represents a share higher than $50 \%[7,14]$ of the overall consumption. For this reason, carrying out an energy audit of the lighting system is important in order to identify energy saving interventions that are simple to implement, enabling significant reductions of the energy consumption and of the related cost $[15,16]$.

In this paper, using the case study of the historical building named Palazzo Medici in Pisa (Italy), which currently houses the headquarters of the Prefecture of Pisa, the authors describe how it is possible to conduct an energy audit activity for the lighting system and they show how, for this type of buildings, it is possible to obtain significant energy savings with interventions of refurbishment of the lighting system. The results of the evaluations described in the paper, although based on a case study, can be extended to numerous historical buildings used as public offices, given that the characteristics of the building envelope, the lighting system, and the building use are common to numerous buildings which can be found in the centres of Italian historical cities.

\section{Material: The Historical Building Used as Case Study}

Palazzo Medici (also known as Palazzo Vecchio) is a building of great historical and artistic value, which was built in the eleventh century [17]. It is located in the city centre of Pisa, on the banks of the Arno river (see Figure 1).

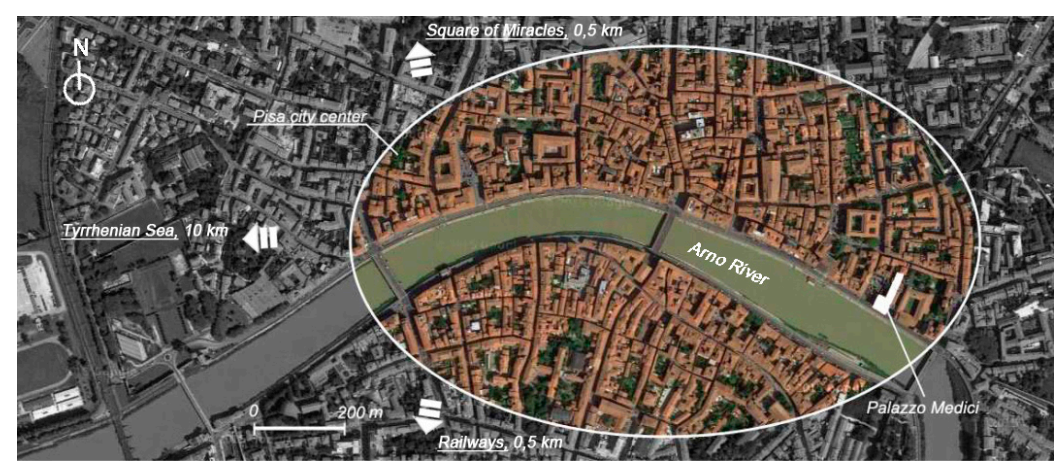

Figure 1. Aerial view of Pisa with positioning of Palazzo Medici. 
The building derives from the expansion of an old tower-house (typical building for the town of Pisa, which served for both residential and defensive use). Built originally outside the city, in an almost rural area around the monastery of San Matteo, the building has been inhabited by the illustrious families of Pisa as Casapieri and later D'Appiano, who expanded the building, reinforcing the part overlooking the Arno river, and created a vast backyard. After a series of vicissitudes, the Medici family took possession of the building in 1441, considering the strategic location, because it was in front of the Cittadella Nuova that was just realized in the fifteenth century. The building became the first ducal residence of the Medici family in Pisa. The building has undergone some renovation and partial expansion under the guidance of well-known Tuscan architects, such as Giovan Battista di Marco del Tasso and Baccio Bandinelli. The most impressive renovation work was conducted in 1871 based on a project of the architect Ranieri Simonelli, commissioned by the marchioness Vittoria Spinola, daughter of Vittorio Emanuele II, owner of the building at the time. Since 1929 the building houses the headquarters of the Prefecture of Pisa, its offices, and the residence of the Prefect.

The building consists of three floors, as shown in Figure 2, with a covered area of $1200 \mathrm{~m}^{2}$. Of the three floors, the third is entirely allocated to public offices (net floor area of $930 \mathrm{~m}^{2}$ ), while the ground floor and the first floor are partly allocated to public offices (net floor area of $410 \mathrm{~m}^{2}$ for each floor) and partly allocated to the residence of the Prefect and to other private-use environments.

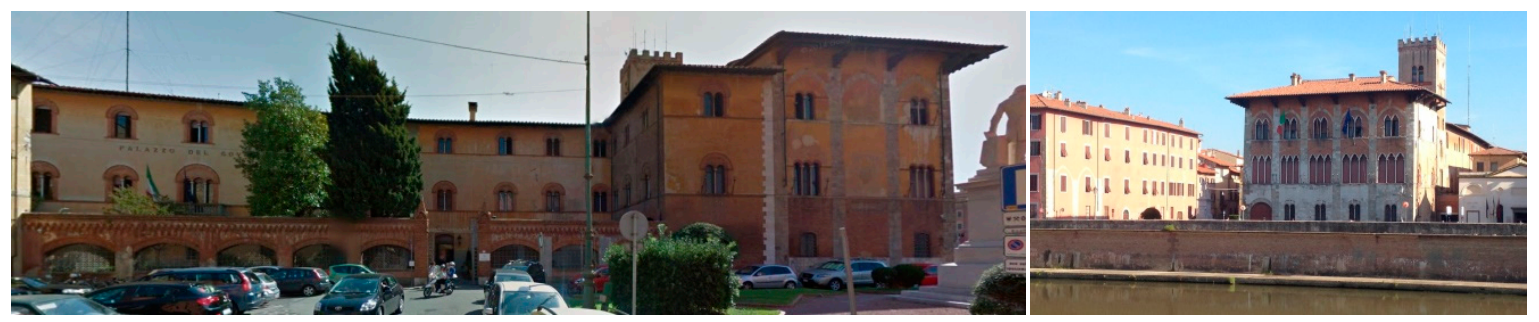

(a)

(b)

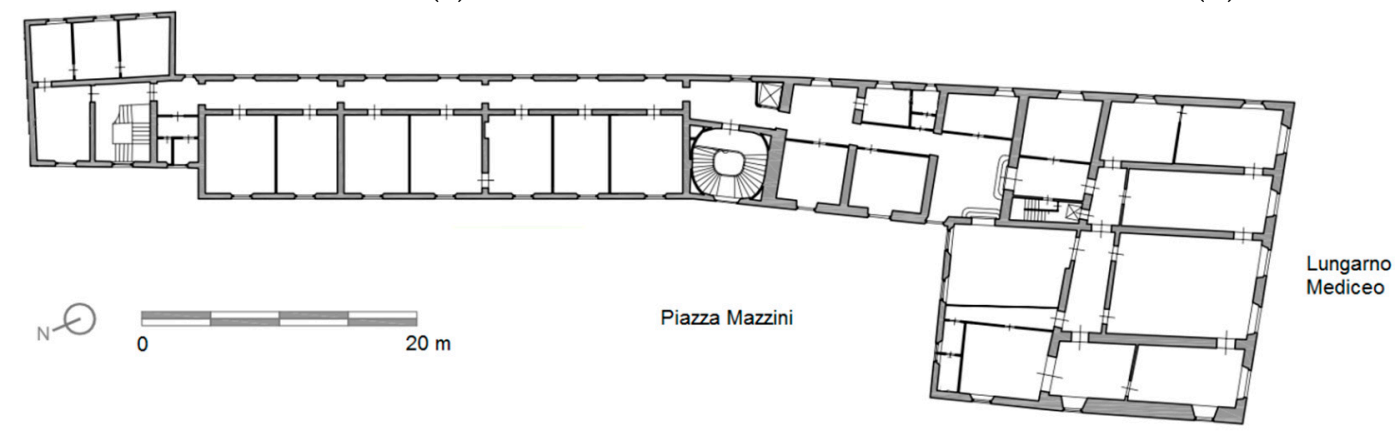

(c)

Figure 2. Palazzo Medici in Pisa: (a) Western front view; (b) Southern front view; and (c) A schematic plan of the second floor.

The results presented in this paper are related only to the portion of the building intended to public offices (the other portions are disregarded), which is characterised by a net floor area of $1750 \mathrm{~m}^{2}$ and a gross volume of $9500 \mathrm{~m}^{3}$.

In Table 1 the main geometrical dimensions are summarized for the analysed portion of the building. The building was subjected to an energy audit, carried out by the authors in the period May 2013-September 2014. 
Table 1. Palazzo Medici: volumes and areas used as public offices for each floor.

\begin{tabular}{cccccc}
\hline \multirow{2}{*}{ Geometrical Features } & \multirow{2}{*}{ Unit } & \multicolumn{3}{c}{ Floor } & \multirow{2}{*}{ Total } \\
\cline { 3 - 5 } & & Ground & 1st & 2nd & \\
\hline Gross volume & \multirow{2}{*}{$\left(\mathrm{m}^{3}\right)$} & 2230 & 2230 & 5040 & 9500 \\
Net volume & 1560 & 1560 & 3470 & 5190 \\
\hline Gross floor area & \multirow{2}{*}{$\left(\mathrm{m}^{2}\right)$} & 510 & 510 & 1180 & 2200 \\
Net floor area & & 410 & 410 & 930 & 1750 \\
\hline
\end{tabular}

\section{Method: The Energy Audit for the Lighting Systems}

Although lacking an international standardization on the detailed modalities to conduct an energy audit for a historical building intended for a public function so relevant as that of a Prefecture, the energy audit of Palazzo Medici was carried out according to the latest European guidelines in this regard $[14,18,19]$. The fundamental steps, performed by the authors during the energy audit activity, can be summarized as follows:

I. Historical data analysis of the energy consumption of the building for the last five years, through retrieval and consultation of the filed documentation (i.e., billing, invoicing);

II. Detailed relief of the building geometry, the envelope features, and the energy systems;

III. Development of a calculation model for the evaluation of the thermal, electrical, and primary energy demands;

IV. Comparison between ascertained and calculated energy demands;

V. Proposals of different interventions for energy saving, concerning to the building envelope and the energy systems;

VI. Cost-benefit analysis for the proposed solutions.

Particular attention was paid to the analysis of the lighting systems, which are the subjects of the energy saving interventions described later, since for the buildings are used for public functions (especially public offices) and the electrical energy consumption for lighting usually represents a significant share of the overall primary energy consumption of the building $[7,14]$.

To perform an energy audit specifically dedicated to the lighting system it is possible to repeat, in detail, the steps from I to VI of the general procedure of an energy audit, with some important observations. As for the step I, it is necessary to observe that the historical buildings very often have no energy meters specifically dedicated to the lighting systems. Therefore, it is usually not possible to obtain the electrical energy consumption due to only the artificial lighting, but this consumption is contained in the global electrical consumption detectable by the filed documentation. This has significant repercussions on the successive steps from II to IV, in fact forcing the auditor to do a very detailed survey of all of the electrical equipment that contributes to the electrical consumption (not only the lighting system), taking over their operational characteristics and mode of use (ignition timing, management techniques, etc.) and interviewing users and maintainers. Obviously, the mathematical model for the evaluation of the electrical consumption should not be limited to the lighting system, but must be extended to all of the electric equipment in order to compare the calculated consumption and the ascertained one. If the model is made accurately and its results are in good agreement with the ascertained values, then it is possible to evaluate energy saving interventions on the lighting system and assess their anticipated benefits for each intervention.

For the case study, the lighting system is composed by two sub-systems: an indoor lighting sub-system (necessary to guarantee the efficient and safe execution of the visual tasks for both employees and visitors, hereinafter simply named the indoor lighting system) and an outdoor lighting sub-system (mainly used to provide architectural lighting to the facades and the gardens of the building, hereinafter simply named the outdoor lighting system). For these lighting sub-systems a 
detailed survey of all the luminaires and the installed lamps was conducted, identifying their technical and operating features. To facilitate the survey activity and the data collection on indoor and outdoor lighting sub-systems, some sheets were prepared, to fill in for each type of luminaire. Each data collection sheet contains the main electrical and photometric data of the related luminaire. An example of the data collection sheet is shown in Figure 3 for a luminaire of the indoor lighting system.

\begin{tabular}{|c|c|c|c|}
\hline \multirow[t]{2}{*}{$\begin{array}{l}\text { Luminaires } \\
\text { ID }\end{array}$} & $\begin{array}{l}\text { Luminaire } \\
\text { picture }\end{array}$ & $\begin{array}{c}\text { Number } \\
\text { of luminaires for floor }\end{array}$ & $\begin{array}{l}\text { Total number } \\
\text { of luminaires }\end{array}$ \\
\hline & 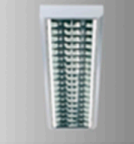 & $\begin{array}{l}\text { Ground: } 5 \\
\text { First: } 0 \\
\text { Second: } 15\end{array}$ & 20 \\
\hline \multicolumn{4}{|c|}{ More frequent installation room: offices with video terminal workstations } \\
\hline \multirow{3}{*}{\multicolumn{2}{|c|}{$\begin{array}{l}\text { Luminaire description: } \\
\text { ceiling mounted luminaires }\end{array}$}} & \multicolumn{2}{|l|}{ Number of lamps: 2} \\
\hline & & \multicolumn{2}{|c|}{ Electrical input power (W): 136} \\
\hline & & \multicolumn{2}{|l|}{ Optical efficiency $(\%): 52$} \\
\hline \multirow{4}{*}{\multicolumn{2}{|c|}{$\begin{array}{l}\text { Single lamp description: } \\
\text { fluorescent tube }\end{array}$}} & \multicolumn{2}{|c|}{ Electrical nominal power $(\mathrm{W}): 58$} \\
\hline & & \multicolumn{2}{|c|}{$\begin{array}{l}\text { Luminous flux (klm): } 5200 \\
\text { Color temperature }(\mathrm{K}): 4000\end{array}$} \\
\hline & & Color temperature $(\mathrm{K}): 40$ & \\
\hline & & \multicolumn{2}{|l|}{ Color rendering index: $>80$} \\
\hline
\end{tabular}

Figure 3. Example of the data collection sheet for a luminaire of the indoor lighting system.

\section{Results}

From the historical analysis of the energy consumptions of the building (step I, see previous section), developed through the analysis of the filed documentation (billing, invoicing) of the last five years, it was possible to determine the average annual consumption for each energy carrier: $41,400 \mathrm{~m}^{3}$ of natural gas and $164 \mathrm{MWh}$ of electrical energy, which result, respectively, in $413 \mathrm{MWh}$ and $397 \mathrm{MWh}$ of primary energy (determined by using a lower calorific value of $9.5 \mathrm{kWh} / \mathrm{m}^{3}$ for the natural gas and the following conversion factors from energy carriers to primary energy [20]: 1.05 for natural gas and 2.42 for electrical energy). Figure 4 shows the trend of the average annual consumption of primary energy during the year. The average annual consumption of primary energy is $810 \mathrm{MWh}$ /year, divided nearly equally between natural gas (51\%) and electrical energy (49\%). Evaluating only the energy consumption for the winter heating, as is usually done, by considering the natural gas consumption (used only for the air-conditioning during the winter season) and the net floor area, an energy performance indicator for winter heating $\mathrm{EPi}=236 \mathrm{kWh} / \mathrm{m}^{2} \mathrm{year}$ is obtained, similarly to what was obtained for other historical buildings [21].

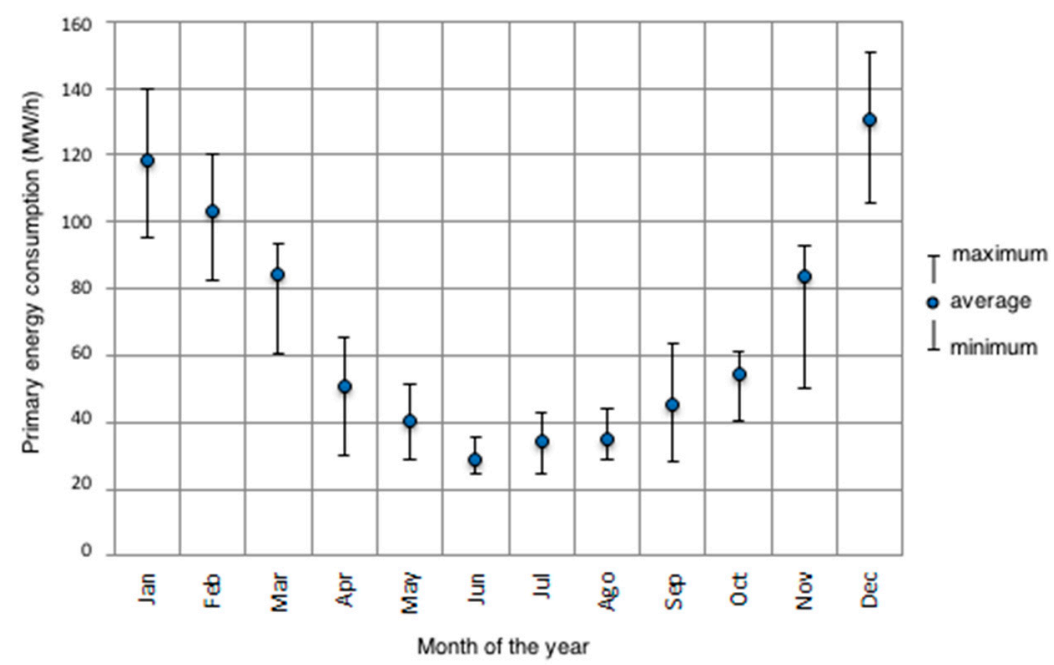

Figure 4. Trend of the average annual consumption of primary energy. 
During the detailed relief activity (step II), all significant characteristics of the building and of its energy systems, which are able to influence the energy consumption, were acquired. By limiting the discussion of the results to those obtained for the lighting system, it is important to note that it is characterized by different luminaires (about 40 different types), of which some typical examples are shown in Figure 5. Some luminaires have a significant historical and artistic value (e.g., see Figure 5a,d), while others, although not recently installed, have no particular artistic feature (e.g., see Figure 5b,c,e).

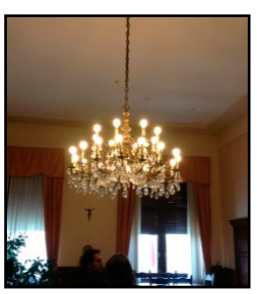

(a)

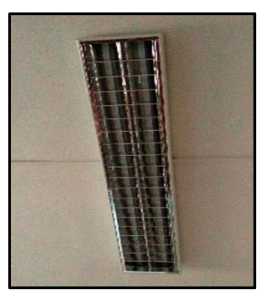

(b)

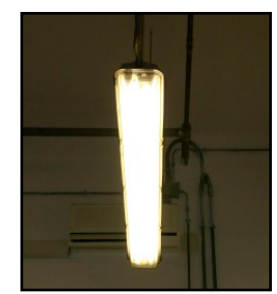

(c)

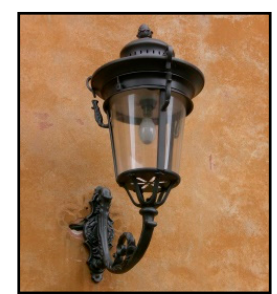

(d)

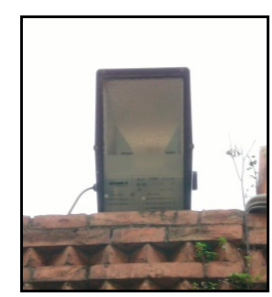

(e)

Figure 5. Relief of the lighting system, examples of: (a) historical luminaires; (b) luminaires for offices and for (c) archives; (d) historical lanterns and (e) perimetral luminaires.

Even the installed lamps are of different types: incandescent, fluorescent, halogen, metal halide and, in the case of the outdoor lighting, also sodium vapour and mercury vapour lamps. In Table 2, for the purpose of the energy assessment, the results of the survey of the lighting system are summarized. In Table 2, the installed electrical powers, grouped by the type of environment and type of lamp, are shown. It should be noticed that the turning-on of numerous luminaires are often controlled by a single manually-operated switch; this limits the possibility of selecting the number of lamps to be turned-on, according to the actual need of artificial light and, thus, to save energy.

Table 2. Results of the detailed survey of the indoor and outdoor lighting systems.

\begin{tabular}{cccccccc}
\hline Lighting System & \multicolumn{6}{c}{ Installed Power, $\mathbf{P}_{\mathbf{T}}(\mathbf{W})$, for Each Lamp Type } \\
\hline \multirow{6}{*}{ Indoor } & $\mathbf{H}$ & $\mathbf{M H}$ & $\mathbf{C F}$ & $\mathbf{F T}$ & $\mathbf{I}$ & Total \\
& & $\mathbf{( 3 2 )}$ & $\mathbf{( 2 0 )}$ & $\mathbf{( 2 9 0 )}$ & $\mathbf{( 1 5 0 )}$ & $\mathbf{( 1 0 5 )}$ & $\mathbf{( 5 9 7 )}$ \\
\hline \multirow{4}{*}{ Rooms } & Staff offices & 1000 & 1200 & 60 & 7140 & 4200 & 13,600 \\
& Meeting rooms & - & 380 & 420 & - & 360 & 1160 \\
& Archives & 240 & - & - & 1660 & 60 & 1960 \\
& Corridors & 930 & - & 4970 & - & 860 & 6760 \\
& Stairs and halls & - & - & 580 & - & 800 & 1380 \\
& Bathrooms & - & - & 380 & 560 & - & 940 \\
\hline \multirow{6}{*}{ Facade } & Outdoor & $\mathbf{H}$ & $\mathbf{M H}$ & $\mathbf{C F}$ & $\mathbf{H P S}$ & $\mathbf{M V}$ & Total \\
& & $\mathbf{( 7 )}$ & $\mathbf{( 2 8 )}$ & $\mathbf{( 1 1 )}$ & $\mathbf{( 4 )}$ & $\mathbf{( 9 )}$ & $\mathbf{( 5 9 )}$ \\
\hline & Northern & - & 70 & - & - & - & 70 \\
& Western & 1050 & 3520 & 2630 & - & 1280 & 8840 \\
& Southern & 240 & - & - & - & - & 240 \\
& Eastern & 240 & 4120 & - & 4800 & 1440 & 10,600 \\
\hline
\end{tabular}

The symbols used for the lamp types are: $\mathrm{H}=$ halogen, $\mathrm{MH}=$ Metal halide, $\mathrm{CF}=$ compact fluorescent, FT = fluorescent tube, I = incandescent, HPS = high pressure sodium, MV = mercury-vapour. In the brackets the total number of each lamp type is indicated.

On the basis of the data collected during the historical analysis (step I), a calculation model for the evaluation of the thermal, electrical, and primary energy demands was carried out (step III). The model was developed by using the methodologies indicated in the technical standards in force nowadays for the air-conditioning, domestic hot water production, and lighting energy demands evaluation [22,23]. The results obtained from the calculation model were in good agreement with the results of the historical analysis, and the percentage difference between the simulated and actual 
(invoicing and billing) primary energy consumptions was less than $10 \%$, for all years of the analysed time period (2009-2013).

By using the calculation model, it was possible to highlight the percentage of the different energy uses on the total annual energy consumption. In particular, for the electrical energy, Figure 6 shows the percentage distribution of the consumption among the different energy uses, from which it is possible to note that the most significant part is that due to the lighting (indoor and outdoor lighting) which exceed $60 \%$, and are consequently about a third of the total primary energy consumed (see also previous section). Eighty percent of the consumption for lighting (51\% of the overall electrical energy consumption) can be attributed to the indoor lighting system, while the remaining $20 \%$ ( $13 \%$ of the overall electrical energy consumption) can be attributed to the outdoor lighting system (see Figure 6).
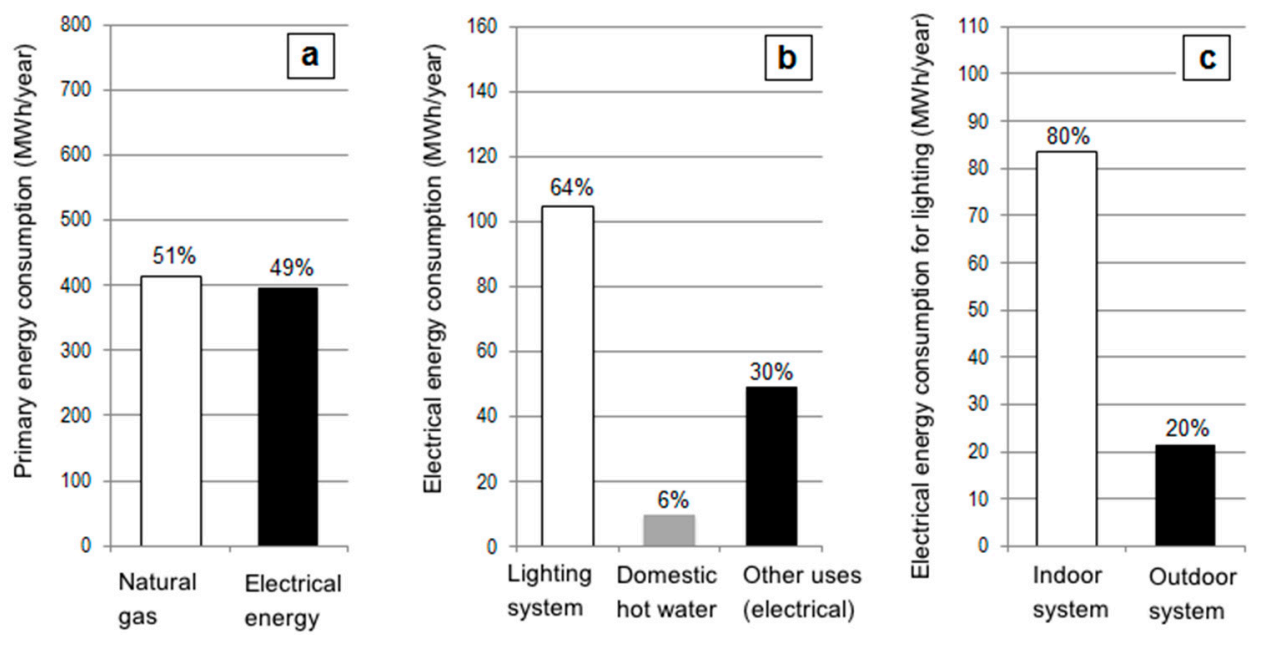

Figure 6. Distribution of the calculated consumptions: (a) Primary energy; (b) Electrical energy; and (c) Electrical energy used for lighting.

Given the obtained results, it seems of interest to pay attention to some interventions with which significant energy savings on the lighting consumptions can be achieved. This type of interventions is generally non-invasive, such as simple lamp replacement in existing luminaires $[15,24,25]$, and as a result is particularly suited to buildings for which the preservation of artistic value is a fundamental prerequisite.

\section{Discussion}

From the results obtained in the previous steps, techno-economic proposals for reducing energy consumptions of the indoor and outdoor lighting systems were analysed. The proposal that are described and discussed in detail arise from a broader evaluation conducted by the authors on a total of 37 possible interventions or combinations of interventions concerning not only the lighting systems, but also the building envelope and the air-conditioning system. The interventions on the lighting systems, however, are of easier implementation, also from the point of view of the manager of the building, because they have a greater reduced cost compared to other types of interventions and they have advantageous payback times. All of the analysed interventions are such as to enable improved energy efficiency without reducing the average comfort conditions currently present and, in some cases, enhancing aspects of health and safety in the workplace, which are fundamental requirements especially in building used for public functions [26-28].

In the analysis of the achievable annual energy savings, in the evaluation of investment costs and payback times, in the identification of the technical proposals for greater convenience (composed of one or more interventions on the lighting system), the guidelines on the implementation of the cost-optimal methodology in EU countries were followed [29]. 
The analysed interventions on the lighting system are divided into interventions on the indoor lighting system (I) and interventions on the outdoor lighting system $(\mathrm{O})$. For the first group, the following interventions were considered: replacement of the incandescent lamps with compact fluorescent lamps in the historical luminaires, keeping the same shape of the lamps for aesthetic reason (I1a); replacement of the incandescent lamps with LED lamps in the historical luminaires, keeping the same shape of the lamps (I1b); replacement of the incandescent lamps and of the fluorescent lamps (both compact and linear) with LED lamps in all the luminaires, keeping the same shape of the lamps in the historical luminaires (I1c); installation of natural light sensors for automatic switch-off of some luminaires in the corridors, staff offices, and meeting rooms (I2); installation of motion sensors to automatically switch on and off of the luminaires in the bathrooms and in the archives (I3). Interventions I1a, I1b, and I1c are alternative solutions and, for this reason, they have been indicated with the same code I1. For the selection of the new lamps, it was decided to keep constant the luminous flux emitted by the replaced lamps. That choice was made following a series of experimental measurements, carried out by the authors on a significant sample of the rooms of the building. From the experimental measurements it was possible to observe illuminance values satisfying the minimum values required by the technical standards $[26,30]$ for the main visual tasks performed in the examined rooms.

For the second group the following interventions were considered: replacement of obsolete floodlights used for the perimetral outdoor lighting with LED floodlights (O1); and the installation of a timer for the programmed switch-on and -off of the luminaires used for the garden lighting $(\mathrm{O} 2)$.

As for the indoor lighting system, using the calculation model developed for the evaluation of the lighting energy demands, the evaluation of the Lighting Energy Numeric Indicator (LENI) was conducted in accordance to the "complete" method indicated in [23], where:

$$
\mathrm{LENI}=\mathrm{W} / \mathrm{S}
$$

where $\mathrm{S}\left(\mathrm{m}^{2}\right)$ is the net floor area and $\mathrm{W}(\mathrm{kWh} /$ year $)$ is the total annual electrical energy used for lighting. In particular $\mathrm{W}$ can be calculated as [23]:

$$
\mathrm{W}=\mathrm{W}_{\mathrm{L}}+\mathrm{W}_{\mathrm{P}}
$$

where $W_{L}$ is the annual electrical energy required to fulfil the illumination function and purpose in the room, $W_{P}$ is the annual electrical parasitic energy required to provide charging energy for emergency lighting and for standby energy for lighting controls. The annual lighting energy $\mathrm{W}_{\mathrm{L}}$ was calculated as [23]:

$$
\mathrm{W}_{\mathrm{L}}=\left(\mathrm{P}_{\mathrm{T}} \cdot \mathrm{F}_{\mathrm{C}} \cdot \mathrm{F}_{\mathrm{O}} \cdot\left(\mathrm{t}_{\mathrm{D}} \cdot \mathrm{F}_{\mathrm{D}}+\mathrm{t}_{\mathrm{N}}\right)\right) / 1000
$$

where $\mathrm{P}_{\mathrm{T}}(\mathrm{W})$ is the total installed electrical power for lighting, $t_{\mathrm{D}}(\mathrm{h})$ is the daylight usage time, $t_{N}(h)$ is the non-daylight usage time, $F_{C}$ (d.u.) is the constant illuminance factor, $F_{O}$ (d.u.) is the occupancy dependency factor, and $\mathrm{F}_{\mathrm{D}}$ (d.u) is the daylight dependency factor. The annual lighting energy $W_{P}$ for the case study building was estimated as the product of the standard consumption of $6 \mathrm{kWh} / \mathrm{m}^{2}$ year [23] and the net floor area S (see Table 1).

The LENI was calculated for the current state and, as a result of each intervention, proposed for improving the energy efficiency of indoor lighting system (I1-I3). In Table 3 the results obtained from the calculation are reported. As can be seen from the data shown in Table 3, the largest reduction of the LENI is obtained with the I1c intervention, after which the LENI is reduced by $52 \%$ and, consequently, the electrical energy saving (EES) is $39.0 \mathrm{MWh}$ /year. The electrical energy saving was evaluates as $\mathrm{EES}=\mathrm{W}_{\mathrm{L} 0}-\mathrm{W}_{\mathrm{LI}}$, where $\mathrm{W}_{\mathrm{L} 0}$ and $\mathrm{W}_{\mathrm{LI}}$ are the values of the annual electrical energy required to fulfil the illumination function in the case of the current state $\left(\mathrm{W}_{\mathrm{L} 0}\right)$ and in the case of the analysed intervention $\left(\mathrm{W}_{\mathrm{LI}}\right)$. 
Table 3. Results of LENI evaluations for the current state and for the different energy saving interventions on the indoor lighting system.

\begin{tabular}{|c|c|c|c|c|c|c|}
\hline \multirow{2}{*}{ Parameter } & \multirow{2}{*}{ Current State } & \multicolumn{5}{|c|}{ Energy Saving Intervention } \\
\hline & & I1a & I1b & I1c & I2 & I3 \\
\hline $\mathrm{P}_{\mathrm{T}}(\mathrm{kW})$ & 25.8 & 21.2 & 20.4 & 10.2 & 25.8 & 25.8 \\
\hline $\mathrm{F}_{\mathrm{C}}$ & 1 & 1 & 1 & 1 & 1 & 1 \\
\hline $\mathrm{F}_{\mathrm{O}}$ & 1 & 1 & 1 & 1 & 1 & 0.95 \\
\hline $\mathrm{F}_{\mathrm{D}}$ & 1 & 1 & 1 & 1 & 0.85 & 1 \\
\hline$t_{D}(h)$ & 2250 & & & 2250 & & \\
\hline$t_{N}(h)$ & 250 & & & 250 & & \\
\hline $\mathrm{W}_{\mathrm{L}}(\mathrm{MWh})$ & 64.5 & 53.1 & 51.1 & 25.5 & 55.8 & 61.3 \\
\hline LENI (kWh/m² year) & 42.9 & 36.3 & 35.2 & 20.6 & 37.9 & 41.0 \\
\hline
\end{tabular}

The use of control systems, in order to better exploit the contribution of natural light, (I2) allows a reduction of the LENI by about $12 \%$ with an EES of $8.7 \mathrm{MWh}$ /year. Note that the use of control systems, in order to better exploit the contribution of natural light, is allowed in the case study (historical building used as public offices) as they are not present artworks that need special protection from solar radiation. Considering the combination of the three compatible interventions I1c, I2, and I3, it is possible to obtain a LENI of $18.0 \mathrm{kWh} / \mathrm{m}^{2}$ year with an overall reduction of $58 \%$ and an EES up to $43.5 \mathrm{MWh} /$ year.

In order to evaluate the economic benefits related to the described interventions, an economic analysis was conducted for a reference period of 10 years. Before introducing the results, which are discussed with special reference to the lamp replacement interventions, it is necessary to provide information on the economic items considered for the calculation.

For each proposed interventions the initial investment $\operatorname{cost}\left(\mathrm{C}_{\mathrm{I}}\right)$, the operating $\cos t\left(\mathrm{C}_{\mathrm{O}}\right)$, and the maintenance $\operatorname{cost}\left(\mathrm{C}_{\mathrm{M}}\right)$ were calculated. The parameter $\mathrm{C}_{\mathrm{I}}$ is given by the product of the number of installed sources and their all-inclusive unit cost (which takes into account the supply, installation, and disposal costs usually applied in Italy). The evaluation was done considering that the lamps replacement is funded by own funds, for this reason the $C_{I}$ was placed in the year of the installation of the new lamps. The parameter $C_{O}$ is due to the energy consumption when the lighting system is turned on and it depends on the actual electrical installed power for lighting, the usage times and the hourly rate of electrical energy (estimated at $0.25 € / \mathrm{kWh}$ according to the all-inclusive tariff derived from billing). In the economic analysis, for the usage times (daylight usage time and non-daylight usage time) the standard values suggested in [23] for office buildings were used (see Table 3); these values were considered to be representative of the case study following the results of an interview with the office workers about the usage profiles of the building. The parameter $C_{M}$ depends on the frequency $(\tau)$ of the scheduled maintenance for the luminaires [31], which are necessary in order to guarantee that the lighting requirements are satisfied. $C_{M}$ was evaluated considering the replacement of all of the lamps at each scheduled maintenance cycle. The frequency $\tau$ of the scheduled maintenance varies with the function of the lamp type and the room type, is influenced by the lighting requirements, which need to be satisfied, and by the technical data about the lamp survival and lamp lumen maintenance provided by the manufacturers. Assuming a maintenance factor of 0.8 (typical value used for an office building [31]) and the data provided by the manufacturers, for the case study the values of the maximum usage times (maximum times beyond which the lamps must be replaced) are: $2500 \mathrm{~h}$ for the incandescent lamps, $7500 \mathrm{~h}$ for the fluorescent lamps, and 15,000 $\mathrm{h}$ for the LED lamps. Through these calculated values, it has been possible to evaluate: $\tau=1$ year for the incandescent lamps, $\tau=3$ years for the fluorescent lamps, and $\tau=6$ years for the LED lamps. $C_{O}$ and $C_{M}$ are referred to different years, with respect to $C_{I}$; for this reason a discounting procedure with a discount rate $(\mathrm{r})$ of $4 \%$ was applied. The discount rate is defined as the rate at which the investment revenues and costs are discounted in order to calculate its present value [32]. The discounting of the individual cost parameter has 
been done by using the following equation: $C_{D}=C_{K} /(1+r) k$, where $C_{D}(€)$ is the discounted cash flow, $C_{K}(€)$ is the cash flow expected in the k-year and $r$ is the discount rate. To properly assess the economic feasibility of the interventions of lamp replacement it is necessary to take into account the benefits that can be achieved from the economic point of view. The expected benefits were assessed in terms of economic benefit related to the electrical energy saving $\left(\mathrm{B}_{\mathrm{O}}\right)$ and to the reduced maintenance $\left(B_{M}\right)$ associated with the different type of lamps. $B_{O}$ was evaluated considering the value of EES obtained by each intervention and the hourly rate of electrical energy; $B_{M}$ was evaluated considering the cost savings obtained as a result of the maintenance not performed of the replaced lamps in each intervention.

The economic costs and benefits, assessed for the reference period of 10 years, are shown on an annual basis in Table 4 for the interventions I1a, I1b, and I1c. For each intervention, there are both the incoming and outgoing cash flows and it is possible to calculate the payback time (PBT) and the net present value (NPV) [32]. In Figure 7a,b, the values of NPV, as a function of time, are shown in the case of the interventions realized with an investment by own funds and a discount rate of $4 \%$. The economic benefits linked to the interventions are significant. It is possible to note that the NPV values at the tenth year are 22,500 $€$ for the replacement of incandescent lamps with fluorescent lamps (Figure 7a), $25,900 €$ for the replacement of incandescent lamps with LED lamps (Figure 7a) and 65,900 $€$ for the replacement of both incandescent and fluorescent lamps with LED lamps (Figure $7 \mathrm{~b}$ ). In this latter case, the reduced installed power of the LED, combined with their long life time, allows a significant reduction of the operating and maintenance costs in the analysed period.

Table 4. Calculation results: economical parameters for different energy saving interventions (lamp replacement interventions).

\begin{tabular}{ccccc}
\hline \multirow{2}{*}{ Parameter } & \multirow{2}{*}{ Unit } & \multicolumn{3}{c}{ Energy Saving Intervention } \\
\cline { 3 - 5 } & & I1a & I1b & I1c \\
\hline $\mathrm{C}_{\mathrm{I}}$ & $(\mathrm{k} €)$ & 0.70 & 1.65 & 11.52 \\
\hline $\mathrm{C}_{\mathrm{O}}$ & & 1050 & 560 & 3970 \\
$\mathrm{C}_{\mathrm{M}}$ & $(€ /$ year $)$ & 230 & 270 & 1920 \\
$\mathrm{~B}_{\mathrm{O}}$ & & 3900 & 3900 & 13,730 \\
$\mathrm{~B}_{\mathrm{M}}$ & & 170 & 170 & 1570 \\
\hline
\end{tabular}
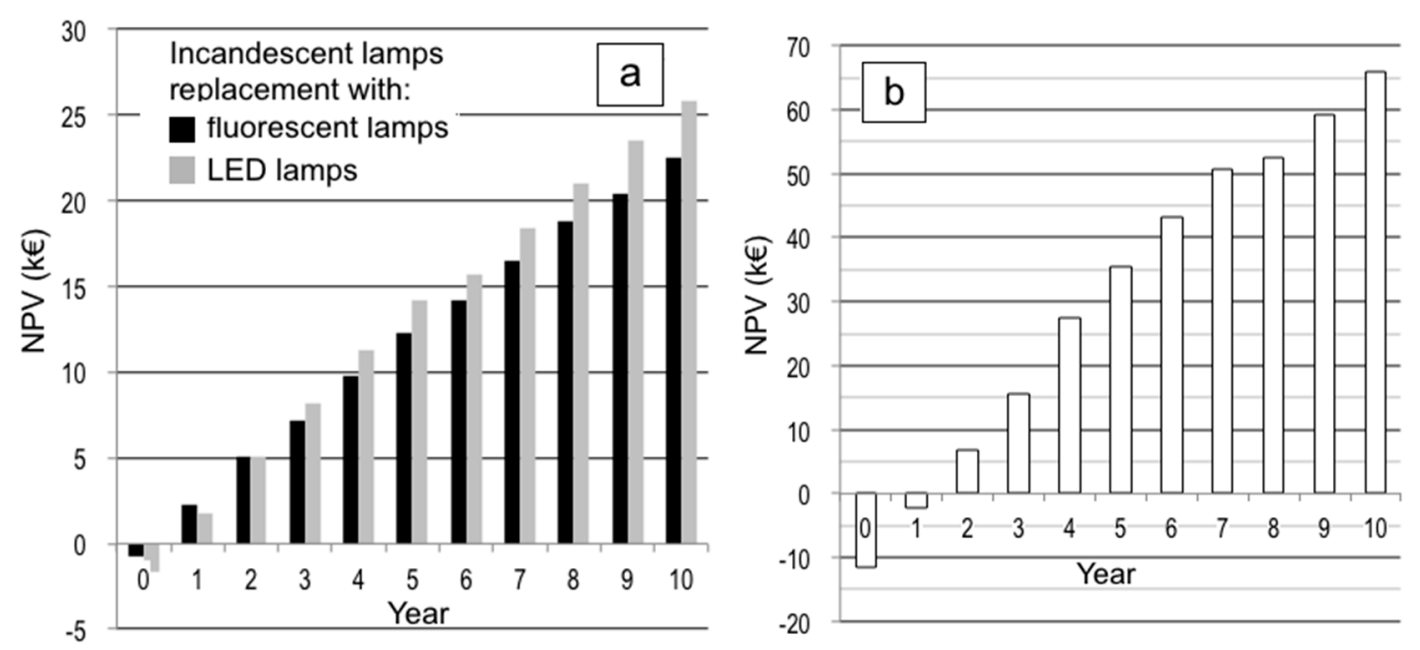

Figure 7. (a) Values of NPV as a function of time in the case of incandescent lamps replacement; and (b) both incandescent and fluorescent lamps replacement.

Comparing the trends indicated in Figure $7 \mathrm{a}$, it can be observed that in the replacement of incandescent lamps, despite the higher initial cost of LED lamps, the intervention I1b (replacement 
with LED lamps) is more advantageous than the intervention I1a (replacement with fluorescent lamps) from the third year. Given the intensive use of the indoor lighting system, the values of the PBT (time for which NPV =0) are also encouraging, as they reflect (see Figure 8) four and six months, respectively, for the replacement of incandescent lamps with fluorescent and LED lamps, and 16 months for the replacement of both incandescent and fluorescent lamps with LED lamps.

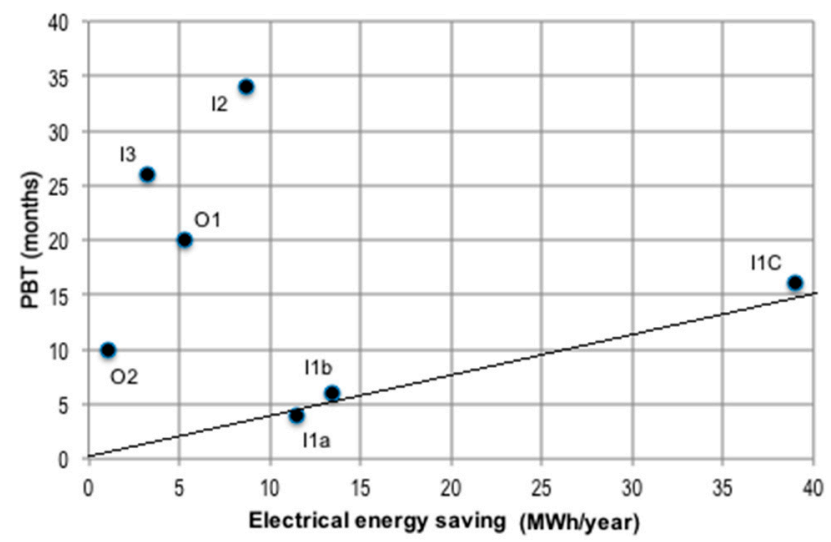

Figure 8. PBT values (months) vs. electrical energy saving (MWh/year) for the seven analysed interventions on the indoor and outdoor lighting systems.

As for the outdoor lighting system, using the calculation model, the evaluation of the energy consumption by considering the electrical installed power for lighting and the nocturnal time usage was conducted. From the calculation results, it was possible to observe that the interventions O1 and $\mathrm{O} 2$ enable, respectively, a reduction percentage of the electrical energy consumption for outdoor lighting of $25 \%$ and $5 \%$, with electric energy savings, respectively, of 5.3 and $1.1 \mathrm{MWh} /$ year. The values of the PBT are 20 and 10 months, respectively, for interventions $\mathrm{O} 1$ and $\mathrm{O} 2$.

Figure 8 summarizes, for the seven considered interventions, the annual energy savings achieved (MWh/year) and the PBT values (months). It is interesting to note that the interventions of lamp replacement for the indoor lighting system (most significant interventions at points I1a, I1b, and I1c in Figure 8) are characterized by a very similar ratio between PBT and electrical energy saving, of about 0.4 months /(MWh/year), as it is possible to see from the black line in Figure 8.

\section{Conclusions}

In this paper, using the case study of the historical building named Palazzo Medici in Pisa (Italy), which currently houses the headquarters of the Prefecture of Pisa, the authors have described how it is possible to conduct an energy audit activity especially dedicated to the lighting system and they have shown how, for this type of buildings, it is possible to obtain significant energy savings with interventions of refurbishment of the lighting system.

For the Palazzo Medici the annual consumption of electrical energy is about $160 \mathrm{MWh} /$ year of which over $60 \%$ is due to artificial lighting. This consumption was obtained by a detailed assessment of the filed documentation (i.e., billing, invoicing) for the last five years and by the development of a calculation model able to describe the thermal and electrical behaviours of the building. From the assessment it was possible to identify seven different interventions of refurbishment of the lighting system, characterized by absolute compatibility with the historical and artistic value of the building.

For each intervention a techno-economic evaluation has discussed, showing the achievable energy saving and the economic benefits for a reference period of 10 years. From the evaluation results it is possible to observe that the seven interventions allow electrical energy saving for the artificial lighting variable from a minimum of $1.1 \mathrm{MWh} /$ year for the outdoor lighting system to a maximum of 39.0 MWh/year for the indoor lighting system (related percentage reductions of the electrical energy: 
$5 \%$ for the outdoor lighting system and $52 \%$ for the indoor lighting system). The seven interventions are also advantageous in economic terms, with short payback times variable between 4 months and 34 months.

The results of the evaluations described in the paper, although based on a case study, can be extended to numerous historical buildings used as public offices, given that the characteristics of the building envelope, the lighting system, and the building use are common to numerous buildings which can be found in the centres of Italian historical cities.

Acknowledgments: The authors would express their thankful to the Italian Home Office, especially in the people of Francesco Tagliente, Prefect of the Pisa District during the energy audit activity, and his assistant Stefania Cufaro, for the opportunity and the cooperation in the activity development and also for the grant to the publishing the data. No funding was received for the development of the activity described in this research paper.

Author Contributions: The authors contribute equally to this work. Giacomo Salvadori, Fabio Fantozzi, Michele Rocca and Francesco Leccese conceived and designed the research activity, performed the analytical calculations, analysed the results, wrote the paper.

Conflicts of Interest: The authors declare no conflict of interest.

\section{References}

1. European Committee for Standardization. Energy Audits-Part 1: General Requirements; UNI EN 16247-1; European Committee for Standardization: Brussels, Belgium, 2012.

2. Pagliaro, F.; Cellucci, L.; Burattini, C.; Bisegna, F.; Gugliermetti, F.; de Lieto Vollaro, A.; Salata, F.; Golasi, I. A Methodological comparison between energy and environmental performance evaluation. Sustainability 2015, 7, 10324-10342. [CrossRef]

3. Pasquarella, C.; Balocco, C.; Pasquariello, G.; Petrone, G.; Saccani, E.; Manotti, P.; Ugolotti, M.; Palla, F.; Maggi, O.; Albertini, R. A multidisciplinary approach to the study of cultural heritage environments: Experience at the Palatina Library in Parma. Sci. Total Environ. 2015, 536, 557-567. [CrossRef] [PubMed]

4. Pagliaro, F.; Bukowiecki, E.; Gugliermetti, F.; Bisegna, F. The architecture of warehouses: A multidisciplinary study on thermal performances of Portus' roman store buildings. J. Cult. Herit. 2015, 16, 560-566. [CrossRef]

5. Botsaris, P.N.; Prebezanos, S. A methodology for a thermal energy building audit. Build. Environ. 2004, 39, 195-199. [CrossRef]

6. United Nations Educational. Scientific and Cultural Organization (UNESCO)—World Heritage Centre, World Heritage List. Available online: http://whc.unesco.org/ (accessed on 08 September 2016).

7. Citterio, M.; Fasano, G. Indagine sui Consumi degli Edifici Pubblici (Direzionale e Scuole) e Potenzialità degli Interventi di Efficienza Energetica; Report RSE/2009/165. ENEA (Italian National Agency for New Technologies, Energy and Sustainable Economic Development), 2009. Available online: http://www.enea.it/it/Ricerca_sviluppo/documenti/ricerca-di-sistema-elettrico/condizionamento (accessed on 08 September 2016). (In Italian)

8. Fantozzi, F.; Leccese, F.; Salvadori, G.; Tuoni, G. Energy demand analysis and energy labelling of new residential buildings in Tuscany (Italy). WIT Trans. Ecol. Environ. 2009, 122, 217-229.

9. Caruso, G.; Fantozzi, F.; Leccese, F. Optimal theoretical building form to minimize direct solar irradiation. Sol. Energy 2013, 97, 128-137. [CrossRef]

10. AlAjmi, A.; Abou-Ziyan, H.; Ghoneim, A. Achieving annual and monthly net-zero energy of existing building in hot climate. Appl. Energy 2016, 165, 511-521. [CrossRef]

11. Sanseverino, E.R.; Scaccianoce, G.; Vaccaro, V.; Carta, M.; Sanseverino, R.R. Smart cities and municipal building regulation for energy efficiency. Int. J. Agric. Environ. Inf. Syst. 2015, 6, 1-27. [CrossRef]

12. Fantozzi, F.; Galbiati, P.; Leccese, F.; Salvadori, G.; Rocca, M. Thermal analysis of the building envelope of lightweight temporary housing. J. Phys. Conf. Ser. 2014, 547, 1-10. [CrossRef]

13. Fabbri, K. Energy incidence of historic building: Leaving no stone unturned. J. Cult. Herit. 2013, 14, $25-27$. [CrossRef]

14. Morandotti, M.; Besana, D.; Riccardi, M.P.; Messiga, B.; Cinieri, V.; Basso, E.; Malagodi, M.; Guidetti, V.; Avagliano, R.; Grandi, M.; et al. Studio, Sviluppo e Definizione di Linee Guida per Interventi di Miglioramento per L'efficienza Energetica negli Edifici di Pregio e per la Gestione Efficiente del Sistema Edificio-Impianto; Report RdS/2011/63. ENEA (Italian National Agency for New Technologies, Energy and Sustainable 
Economic Development), 2011. Available online: http://www.enea.it/it/Ricerca_sviluppo/documenti/ ricerca-di-sistema-elettrico/risparmio-energia-settore-civile (accessed on 22 July 2016). (In Italian)

15. Ciampi, G.; Rosato, A.; Scorpio, M.; Sibilio, S. Retrofitting solutions for energy saving in historical building lighting system. Energy Procedia 2015, 78, 2669-2674. [CrossRef]

16. Fantozzi, F.; Leccese, F.; Salvadori, G.; Rocca, M.; Garofalo, M. LED lighting for indoor sports facilities: Can its use be considered as sustainable solution from a techno-economic standpoint? Sustainability 2016, 8 , 618-631. [CrossRef]

17. CLD Libri. Le Case Torri di Pisa; Collana CD Guide; CLD Libri: Pisa, Italy, 1999. (In Italian)

18. De Santoli, L. Guidelines on energy efficiency of cultural heritage. Energy Build. 2015, 86, 534-540. [CrossRef]

19. Burattini, C.; Nardecchia, F.; Bisegna, F.; Cellucci, L.; Gugliermetti, F.; Vollaro, A.D.L.; Salata, F.; Golasi, I. Methodological approach to the energy analysis of uncostrained historical buildings. Sustainability 2015, 7, 10428-10444. [CrossRef]

20. Italian Governement, Ministry of Economic Development. Applicazione delle Metodologie di Calcolo delle Prestazioni Energetiche e Definizione delle Prescrizioni e dei Requisiti Minimi Degli Edifici; Ministry Decree 26/06/2015; Italian Governement, Ministry of Economic Development: Rome, Italy, 2015. (In Italian)

21. Troi, A.; Bastian, Z. Energy Efficiency Solutions for Historic Buildings: A Handbook; Birkhäuser: Basel, Switzerland, 2014.

22. Italian Organization for Standardization (UNI). Energy Performance of Buildings; UNI/TS 11300, Parts 1-3; UNI: Milan, Italy, 2014. (In Italian)

23. European Committee for Standardization. Energy Performance of Buildings_Energy Requirements for Lighting; UNI EN 15193; European Committee for Standardization: Brussels, Belgium, 2008. (In Italian)

24. Gana, C.K.; Sapara, A.F.; Muna, Y.C.; Chongb, K.E. Techno-economic analysis of LED lighting: A case study in UTeM's faculty building. Procedia Eng. 2013, 53, 208-216. [CrossRef]

25. Salata, F; de Lieto Vollaro, A.; Ferraro, A. An economic perspective on the reliability of lighting systems in building with highly efficient energy: A case study. Energy Convers. Manag. 2014, 84, 623-632. [CrossRef]

26. Leccese, F.; Salvadori, G.; Casini, M.; Bertozzi, M. Lighting of indoor work places: Risk assessment procedure. WIT Trans. Inf. Commun. Technol. 2012, 44, 89-101.

27. Leccese, F.; Vandelanotte, V.; Salvadori, G.; Rocca, M. Blue light hazard and risk group classification of 8 W LED tubes, replacing fluorescent tubes, through optical radiation measurements. Sustainability 2015, 7, 13454-13468. [CrossRef]

28. Leccese, F.; Salvadori, G.; Casini, M.; Bertozzi, M. Analysis and measurements of artificial optical radiation (AOR) emitted by lighting sources found in offices. Sustainability 2014, 6, 5941-5954. [CrossRef]

29. Atanasiu, B.; Kouloumpi, I. Implementing the Cost-Optimal Methodology in EU Countries; Buildings Performance Institute Europe (BPIE): Brussels, Belgium, 2013.

30. European Committee for Standardization. Light and Lighting_Lighting of Work Places; UNI EN 12464-1; European Committee for Standardization: Brussels, Belgium, 2011.

31. International Commission on Illumination (CIE). Technical Report_Guide on the Maintenance of Indoor Electric Lighting Systems; CIE 97; International Commission on Illumination: Vienna, Austria, 2005.

32. Dall'O', G. Operating Instructions for the Energy and Environmental Audits of Buildings, 1st ed.; Edizioni Ambiente: Milan, Italy, 2011.

(C) 2016 by the authors; licensee MDPI, Basel, Switzerland. This article is an open access article distributed under the terms and conditions of the Creative Commons Attribution (CC-BY) license (http://creativecommons.org/licenses/by/4.0/). 